\title{
High-dose cyclophosphamide without stem cell rescue in immune- mediated necrotizing myopathies
}

Neurol Neuroimmunol Neuroinflamm 2018;5:e473. doi:10.1212/NXI.0000000000000473

In the Article "High-dose cyclophosphamide without stem cell rescue in immune-mediated necrotizing myopathies" by C.A. Mecoli et al., ${ }^{1}$ the Acknowledgments section should include the following: "CAM was supported by National Institutes of Health/National Institute of Arthritis and Musculoskeletal and Skin Diseases grant T32AR048522.” The authors regret the omission.

\section{Reference}

1. Mecoli CA, Lahouti AH, Brodsky RA, Mammen AL, Christopher-Stine L. High-dose cyclophosphamide without stem cell rescue in immune-mediated necrotizing myopathies. Neurol Neuroimmunol Neuroinflamm 2017;4:e381. 


\section{Neurology \\ Neuroimmunology \& Neuroinflammation}

\section{High-dose cyclophosphamide without stem cell rescue in immune-mediated necrotizing myopathies \\ Neurol Neuroimmunol Neuroinflamm 2018;5; \\ DOI 10.1212/NXI.0000000000000473}

This information is current as of June 5, 2018

Updated Information \&

Services

References

Permissions \& Licensing

Reprints including high resolution figures, can be found at:

http://nn.neurology.org/content/5/4/e473.full.html

This article cites 1 articles, 0 of which you can access for free at: http://nn.neurology.org/content/5/4/e473.full.html\#\#ref-list-1

Information about reproducing this article in parts (figures,tables) or in its entirety can be found online at:

http://nn.neurology.org/misc/about.xhtml\#permissions

Information about ordering reprints can be found online: http://nn.neurology.org/misc/addir.xhtml\#reprintsus

Neurol Neuroimmunol Neuroinflamm is an official journal of the American Academy of Neurology.

Published since April 2014, it is an open-access, online-only, continuous publication journal. Copyright $($ ) 2018 American Academy of Neurology. All rights reserved. Online ISSN: 2332-7812.

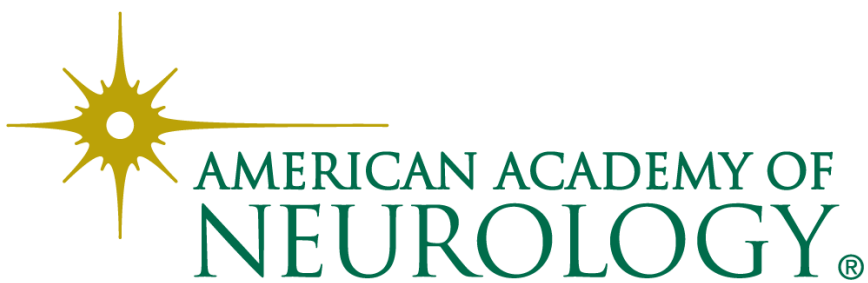

